\section{ATTRACTIVE, AFFORDABLE CABINETRY}

Whether creating a new surgery from scratch or replacing your original units, Tavom has the experience and the range of dental cabinetry to suit any client's needs.

Operating since 1975, Tavom's reputation as one of the top providers of dental furniture and cabinetry is well deserved. Harnessing over 30 years' experience and using the latest computer aided design, Tavom can alleviate the stress of creating a professional and functional surgery. With the widest range of ergonomic cabinetry in a variety of colours and styles, Tavom is confident it can offer any client a package that is not only attractive but also affordable.

Working to the client's specifications, Tavom's expert team delivers an exceptional level of service when providing elegant, practical and adaptable units that are compliant with all new and existing regulations.

Dentists can feel at ease in the knowledge that Tavom's committed customer care and aftercare team is ready and willing to give high quality service from start to finish.

Reader response number 60

\section{CHILD-FRIENDLY FORCEPS}

Hu-Friedy has expanded its extensive collection of paediatric dental forceps for extractions with the Rainbow Presidential Pedo series. These instruments have been designed in iridescent rainbow colours to make treatment for children as anxiety-free and pleasant as possible. The forceps were especially developed for the anatomical structure of children's teeth. Sensitive tissue and bones are protected during the extraction, thus noticeably enhancing patient comfort.

The extracting forceps for children made by Hu-Friedy allow firm, precise access to milk teeth and root surfaces, therefore ensuring smooth extractions with low risk of complications. The dental forceps in the Pedo series were conceived for small, lower crowns and conically-shaped teeth. The products in the Rainbow Presidential Pedo series are handcrafted from highquality surgical steel which makes them especially sturdy and efficient. In addition, the manufacturer offers a lifelong guarantee for material defects and processing errors.

Reader response number 61

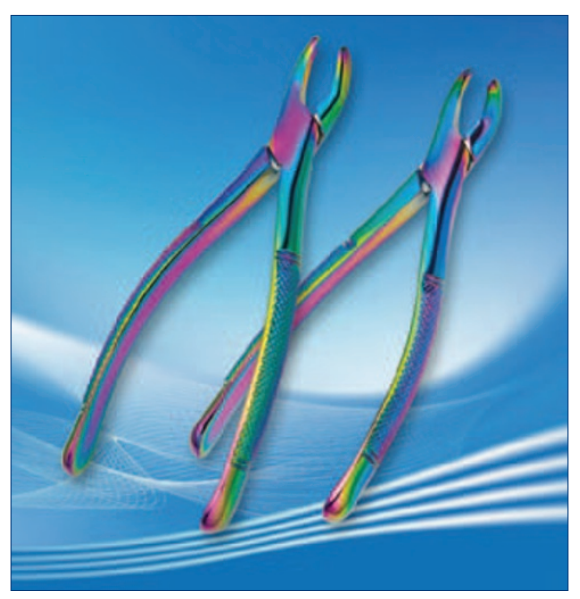

\section{CONNECTED DEFIBRILLATION}

SafeTIC, a leading European provider of innovative technologies, has launched DOC in the UK: the first Connected Operational Defibrillator.

DOC addresses a major public health issue by helping to reduce the mortality rate of heart attacks through the largescale deployment of readily accessible, easy-to-use defibrillators. Surviving an of out-of-hospital sudden cardiac arrest is closely linked to how quickly a shock can be delivered. There is a much greater chance of survival if the casualty is defibrillated within four minutes of the heart attack occurring. When every minute counts, clear, simple and reliable instructions are essential.

When deployed, the DOC defibrillator system automatically triggers an alert and makes contact with an experienced helpdesk operator provided by Mondial Assistance, a world leader in remote medical services. At the same time, a GPS signal gives the operator immediate notification of the exact location of the patient and a call to the emergency services is made.

Companies that sign up to the DOC service package are provided with four hours of training from British Red Cross Training on basic CPR techniques and how to use the defibrillator. Companies equipped with DOC are not responsible for monitoring or maintaining the equipment and can rest assured that the equipment is ready for use at any time. The SafeTIC system is supplied through a monthly subscription agreement which offers peace of mind and an affordable package.

Reader response number 62

\section{SECOND SKIN GLOVES}

Ansell Healthcare has introduced the Micro-Touch Nitrile, a new 100\% latex-free and powder-free nitrile examination glove specially targeted at dental and medical professionals. The Micro-Touch Nitrile provides effective barrier protection, easy donning and more comfort. The new exam glove represents an economical alternative to NRL gloves and comes in a cost-effective 150count packaging with 50\% more gloves per dispenser box. Its white colour provides a high-contrast background that reveals soiling and contamination.

Due to the continued increases in rubber and latex glove prices, nitrile gloves are now progressively replacing latex gloves and another major advantage is the prevention of allergic reactions associated with latex gloves.
Manufactured from premium quality nitrile and 'thermo elastic material' that adapts to the hand's shape, the Micro-Touch Nitrile glove also assures more dexterity and comfort than a latex glove. The glove itself is soft and supple - almost as if the user is wearing a second skin. Micro-textured finger surfaces ensure a good grip on instruments making Micro-Touch Nitrile the optimal choice. Reader response number 63 